\title{
FAKE NEWS: uma definição possível entre a reflexão crítica e a experiência jornalística
}

FAKE NEWS: a possible definition between critical reflection and journalistic experience

\author{
Beatriz BECKER ${ }^{1}$ \\ Francisco Moratorio de Araujo GOES ${ }^{2}$ \\ Universidade Federal do Rio de Janeiro | Brasil
}

\begin{abstract}
Resumo
A partir de entrevistas realizadas com dez reconhecidos jornalistas brasileiros e de uma ampla revisão bibliográfica, este artigo busca contribuir para uma definição conceitual menos difusa das fakenews. $O$ trabalho sugere que as informações falsas tanto desafiam quanto fortalecem o jornalismo profissional. Palavras-chave

Fakenews. Vozes de jornalistas. Reconfigurações do jornalismo. Desordem informativa. Práticas jornalísticas

\section{Abstract}

From interviews conducted with ten well-known Brazilian journalists and a wide bibliographical review, this paper seeks to contribute to a less diffuse conceptual definition of fake news.

The work suggests that false information both challenges and strengthens professional journalism.

Keywords

Fake News. Voices of journalists. Reconfigurations of journalism. Information desorder. Journalistic practices.
\end{abstract}

\section{RECEBIDO EM 19 DE AGOSTO DE 2019}

ACEITO EM 20 DE OUTUBRO DE 2019

${ }^{1}$ Professora do Programa de Pós-Graduação em Comunicação e Cultura da Universidade Federal do Rio de Janeiro (PPGCOM-UFRJ), líder do Grupo de Pesquisa Mídia, Jornalismo Audiovisual e Educação (MJAE) e bolsista de Produtividade do CNPq. Contato: beatrizbecker@uol.com.br.

2 JORNALISTA. Mestre em Comunicação e Cultura pelo Programa de Pós-Graduação em Comunicação e Cultura da Universidade Federal do Rio de Janeiro. Contato: franciscoaraujogoes@gmail.com.

João Pessoa - Brasil | ANO 7 VOL.7 N.1 | JAN./JUN. 2020 | p. 34 a 53 


\section{Contextualizações}

partir das eleições norte-americanas de 2016, que elegeram
Donald Trump como presidente dos Estados Unidos, as fakenews
alcançaram relevância mundial. Ao analisar o caso de vazamento de dados pessoais de milhões de usuários do Facebook para a Cambridge Analytica, Gonzalo (2018) argumenta que esta empresa pode ter usado os dados de cerca de 87 milhões de usuários daquela plataforma social, a maior parte deles situada nos Estados Unidos, para favorecer a vitória de Donald Trump nas eleições norte-americanas de 2016, por meio de "estratégia de micro-alvo baseada em técnicas militares de ataque psicológico" (Idem, p. 25). Trump e outros políticos não tradicionais, como Rodrigo Duterte, presidente das Filipinas, apropriaram-se da expressão fakenews para atacar veículos de imprensa que publicavam reportagens desfavoráveis aos seus programas de governo e, posteriormente, também às suas administrações, o que também ocorreu no Brasil. Durante as eleições presidenciais de 2018, o presidente eleito Jair Bolsonaro e seus filhos, políticos, usavam a expressão fakenews para desqualificar reportagens das quais discordavam, prática que o governo continua a adotar depois da posse. A apropriação da expressão fakenews por atores políticos contribuiu para que acadêmicos e instituições, como a Organização das Nações Unidas para a Educação, a Ciência e a Cultura (Unesco) e a Comissão Européia, considerassem o termo fakenews inadequado para se referir a este problema comunicacional da atualidade, preferindo tratar a questão como parte de um fenômeno contemporâneo mais abrangente: a "desinformação". Análises críticas produzidas na academia e nos veículos informativos também passaram a destacar a inter-relação existente entre a desinformação e os mecanismos de inteligência artificial (algoritmos e robôs), bem como o papel das plataformas Google e Facebook no incremento das chamadas notícias falsas. Evidenciaram ainda o protagonismo do aplicativo WhatsApp como poderosa ferramenta de desinformação, o que também ficou 


\section{ANEORA}

Beatriz BECKER - Francisco GOES

demonstrado nas eleições presidenciais brasileiras. Assim, nos dois últimos anos, a expressão fakenews passou a ocupar um lugar central na agenda social - sobretudo no jornalismo.

Hoje, os meios de comunicação tradicionais se inter-relacionam e se interconectam com uma miríade de suportes digitais na internet. Grandes volumes de informação são disseminados por aplicativos e controlados por sistemas de big data e plataformas, o que relativiza o poder das organizações jornalísticas sobre a produção e o consumo de notícias. A autoridade do jornalismo sobre a escrita da experiência cotidiana e sobre o que é realidade ainda é tensionada pelas empresas de fact-checking, uma vez que a verificação das informações é uma tarefa intrínseca ao jornalismo e os efeitos desses serviços ainda são pouco conhecidos (NYHAN; REIFLER, 2013). No entanto, já é possível observar que veículos de mídia mainstream reagem a este fenômeno e criam departamentos ou seç̧ões para fazer eles mesmos a verificação de fatos e dos discursos dos políticos durante as eleições. As fakenews, entretanto, são disseminadas nas redes e por aplicativos sem possibilidade de controle. O público passa a atuar não apenas como um receptor da informação, mas também como um produtor que customiza o conteúdo noticioso no ambiente midiático convergente. Os conteúdos informativos ganham expressão significativa a partir da descentralização da produção noticiosa na internet, sobretudo na cobertura de acontecimentos sensíveis como as disputas eleitorais, que fazem aflorar as fakenews, corroborando para a ausência de equilíbrio, a irracionalidade e o ódio no debate público. Os vínculos afetivos e emocionais com as notícias são cada vez mais intensos e as opiniões e as crenças pessoais prevalecem sobre os fatos. Trancadas em seus grupos partidários e protegidas pelo filtro de suas bolhas, as pessoas perdem a habilidade de se comunicar com a diversidade de pensamentos e se tornam sectárias. Há uma mudança no equilíbrio de poder entre a audiência e os produtores profissionais de notícias, em decorrência da descrença de parte do 
público nos meios tradicionais de comunicação, e torna-se difícil para as pessoas separarem fatos de ficção (Kakutani, 2018; MARTIN, 2017).

Os mecanismos de inteligência artificial, como os algoritmos, também fazem a seleção dos assuntos e notícias que circulam na internet e em mídias sociais, de acordo com as preferências pessoais e políticas de cada usuário, operando como "filtros-bolha" e reforçando a existência das "câmaras de eco" (PARISIER, 2011). As fakenews tornaram-se tema de preocupação pública pelo seu efeito no campo político, uma vez que têm o poder de influenciar resultados eleitorais nas democracias do mundo ocidental (McNAIR, 2017). As próprias instituições jornalísticas contribuem para amplificar as fakenews e reduzir a mediação do jornalismo no processo de circulação social de informação quando praticam o jornalismo declaratório, a reprodução de declarações interessadas em grandes coberturas políticas e econômicas no Brasil (Meditsch, 2017).

Assim, imbricadas tanto nas lógicas discursivas do jornalismo quanto em formas discursivas hegemônicas ou totalizadoras, as fakenews ganham fôlego, pautam debates públicos e conversações nas redes sociais e são discutidas no país por diferentes instituições, instâncias superiores do judiciário e empresas jornalísticas. No entanto, ainda que os relatos jornalísticos estejam perdendo relevância na construção da verdade dos fatos na atualidade no Brasil e no mundo, sugerimos que as fakenews, contraditoriamente, deflagram a relevância de um jornalismo independente e de qualidade para a democracia em um cenário de intensas reconfigurações da produção e consumo de notícias (Kischinhevsky, 2018). Contudo, observamos que a definição desta expressão ainda é imprecisa. A partir de uma ampla revisão bibliográfica e de entrevistas semiabertas realizadas com dez reconhecidos jornalistas brasileiros, este artigo busca contribuir para uma definição menos difusa para esse fenômeno. Em seguida, apresentamos um mapeamento do pensamento crítico sobre as fakenews e os principais resultados das entrevistas realizadas com os 


\section{ANEORA}

Beatriz BECKER - Francisco GOES

jornalistas. Posteriormente, cruzamos o mapeamento da produção acadêmica sobre as fakenews e sistematizamos quatro características para defini-las ${ }^{3} \mathrm{com}$ o intuito de contribuirmos para ampliar a compreensão deste fenômeno.

\section{Mapeando sentidos das fake News}

A credibilidade jornalística é constituída tanto por quem a enuncia quanto pelo leitor, ou seja, é formada em uma relação entre um determinado veículo e seu público, baseada na confiança de que o jornalismo é um sistema com competência especializada para produzir notícias e traduzir acontecimentos relevantes para a vida social (LISBOA; BENETTI, 2015). Porém, o discurso jornalístico não deixa de estar "envolto no real e na verdade como referentes, além de trazer a imparcialidade e a objetividade como operadores" (RESENDE, 2005, p.92). Ao omitir o lugar do narrador, o discurso jornalístico tenta apagar a ideia de que o jornalista cria acontecimento, e prevalece então o lugar d.o jornalismo como uma instância que enuncia a verdade do fato. Para reforçar sua credibilidade e convocar a audiência ao consumo de suas notícias e exercer a sua mediação no debate público como enunciador confiável, a imprensa se ampara no conceito de "objetividade". A socióloga Gaye Tuchman descreveu a objetividade jornalística como um ritual estratégico para o jornalismo e os jornalistas assegurarem, respectivamente, a sua relevância e o seu papel social, baseada em um conjunto de técnicas, como o uso de fontes especializadas, a escuta e a expressão de pontos de vista diferenciados sobre um fato ou questão, a demonstração de um acontecimento com imagens e o uso de aspas, recursos que ainda são utilizados para justificar a veracidade do relato. No entanto, a construção social da realidade tecida pelo discurso jornalístico ancorada na objetividade é uma aspiração de difícil execução e revela-se frágil quando as empresas jornalísticas não optam pela transparência ao explicitar as suas decisões editoriais, gerando

\footnotetext{
${ }^{3}$ Estas categorias foram elaboradas e sistematizadas a partir de uma ampla revisão bibliográfica em Dissertação de Mestrado defendida e aprovada no PPGCOM-UFRJ, originária deste artigo.
} 
questionamentos sobre procedimentos éticos e de métodos do jornalismo como instituição social (MIRANDA; VIEIRA, 2019). Tais questionamentos, associados ao aprofundamento da polarização política, estimulam a proliferação das fakenews, se sobrepõem à mediação jornalística e tendem a privilegiar a subjetividade sobre a objetividade, a opinião sobre os fatos, a emoção sobre a razão, o conflito sobre o consenso (CASTRO, 2017). Contudo, este fenômeno não está restrito ao jornalismo e às suas relações com os leitores.

$\mathrm{O}$ atual momento histórico coloca em questão valores e ideais que orientaram a vida em sociedade nos últimos séculos no Ocidente.A vida social impactada pela valorização do individualismo e da competitividade na contemporaneidade, também é caracterizada por um descrédito das instituições, sobretudo, dos sistemas político e midiático.Ao mesmo tempo, os cidadãos ficam cada vez mais fragilizados frente ao poder das instituições, sob o risco de ficarem submetidos a protocolos medicalizadores e a modalizações opressoras de sistemas policiais e jurídicos (PRADO, 2017). Movimentos nacionalistas e fundamentalistas, bem como o ódio a estrangeiros, estão em ascensão em diferentes continentes, corroem as instituições democráticas, provocam medo e raiva e se fortalecem à medida que as pessoas, trancadas em seus grupos partidários e protegidas pelo filtro de suas bolhas, perdem a habilidade de se comunicar com a diversidade de pensamentos e se tornam sectárias (KAKUTANI, 2018). Neste contexto, emerge uma desconfiança em relação à própria democracia em um cenário de dificuldades e incertezas econômicas no Brasil e em outros países. Esse fenômeno afeta o jornalismo, tensionado pela superabundância e simultânea fragmentação de conteúdos informativos decorrentes da incorporação de tecnologias digitais na produção, distribuição e compartilhamento de notícias na internet, pelo simultâneo papel de controle e espalhamento de informações de grandes conglomerados multinacionais, como Facebook e Google, pela criação de conteúdos noticiosos 


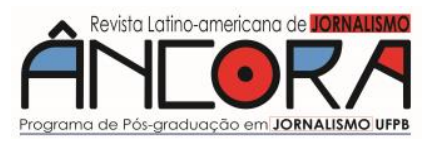

Beatriz BECKER - Francisco GOES

por atores humanos e não humanos e pela proliferação das fakenews, as quais, segundo McNair (2017) seriamo produto de um "caos cultural", resultante da combinação de tendências políticas, tecnológicas e culturais que desafiam estruturas de poder e autoridades. Entretanto, em um cenário de intensas reconfigurações das práticas jornalísticas, as fakenews tanto contribuem para o esvaziamento do poder das organizações jornalísticas sobre a produção noticiosa quanto valorizam a medição do jornalismo na produção e na circulação de informações relevantes e confiáveis.

No trabalho sobre este tema que produziram para o Conselho Europeu, intitulado Relatório Desordem Informacional: em direção a um marco interdisciplinar para a pesquisa e a elaboração de políticas, Wardle e Derakshan(2017)preferem não utilizar a expressão fakenews. Os autores argumentam que estas palavras são inadequadas para descrever o fenômeno de "poluição informacional" que caracteriza o mundo moderno em rede e crescentemente polarizado e ainda foram "apropriadas" por políticos, em diferentes países, para descreverem organizações de mídia cujas coberturas jornalísticas Ihes são desfavoráveis (Idem).Eles estabelecem três categorias para analisar a desordem informacional, valendo-se dos termos, em inglês, "mis", "dis"e "mal-information". A primeira categoria diz respeito a uma informação falsa compartilhada, mas que não causa dano; a segunda corresponde a uma informação deliberadamente falsa com o objetivo de causar algum prejuízo a alguém (pessoa, grupo ou instituição); e a terceira categoria indica a má informação, uma notícia compartilhada para tornar públicas informações que foram produzidas para permanecerem na esfera privada.

Partindo também da ideia de fakenews como uma instância da desinformação, Tandoc Jr., Wei Lime Ling (2017), por sua vez, apontam seis categorias para a compreensão deste fenômeno, amparadas em distintos estudos acadêmicos: 1 . sátiras de notícias, 2. paródias de notícias, 3. fabricação de notícias, 4. manipulação de fotografias, 5. publicidade e relações 
públicas e 6. propaganda política. (TANDOC JR.; WeiLIM; LING, 2017, p.137). Segundo eles, as fakenews suscitam reflexões sobre a natureza da "notícia real" e ponderam que as notícias são "suposta e normativamente" baseadas na verdade, o que faz da expressão fakenews um "oxímoro", o uso conjunto de palavras de sentido contraditório (Tandoc JR.; Wei LIM; Ling, 2017, p.140). Franciscato $(2017$, p. 87$)$ também ressalta que "o termo é uma contradição em si mesmo", e que "qualquer ideia sensata sobre o que é notícia rejeita, por princípio, essa possibilidade de haver um derivativo 'falso'". O autor destaca que o entendimento de notícia circula em torno da ideia de uma "verdade como horizonte que dá sentido à atividade jornalística"; e que "A mentira será sempre a negação da notícia, sua asfixia" (Ibidem).

Guess, Nyhan e Reifler (2018)definem as fakenews como uma nova forma de "desinformação política" e reconhecem que o crescimento do partidarismo e o uso em larga escala das mídias sociais, nos Estados Unidos, criaram o medo da difusão dos chamados "filtros-bolha" ou "câmaras de eco", mas relativizam seus efeitos ao demonstrar que quase seis entre dez pessoas que visitaram sites de fakenews, nas eleições de 2016 nos Estados Unidos, pertencem, na verdade, a um grupo de $10 \%$ de norte-americanos que têm uma "dieta" de informação conservadora. Porém, segundo Prado (2018), um outro aspecto importante das fakenews é o seu formato, uma vez que são estruturadas como notícias reais, e são distribuídas com a ajuda de robôs (bots) para a sua rápida disseminação em diferentes grupos que compartilham interesse por esse tipo de conteúdo. Coromina e Padilla (2018, p. 16) utilizam a expressão fakenews para se referir à "informação abertamente falsa que não tem base em fatos reais e que pode ser refutada usando mecanismos muito básicos de checagem".

Porém, para o Reuters Institute for the Study of Journalism (2017), as fakenews devem ser entendidas como informação sabidamente falsa que circula com um propósito estratégico específico, seja este político, 


\section{ANएORA}

Beatriz BECKER - Francisco GOES

prejudicando ou favorecendo uma determinada pessoa; ou comercial, garantindo dinheiro a quem cria e espalha fakenews. Este fenômeno pode ainda ser compreendido, como notícias "intencionalmente" e "comprovadamente" falsas, com o intuito de enganar os leitores (ALLCOTT; GENTZKOW, 2017). Contudo, verificamos que, apesar dos aspectos convergentes e divergentes que caracterizam as fakenews referidos pelos pesquisadores, a definição deste conceito ainda é difusa.

\section{Vozes de jornalistas}

Com o intuito de conjugara reflexão teórica apresentada coma experiência empírica de jornalistas para apontar uma definição mais precisa deste fenômeno, foram realizadas entrevistas semiabertas com dez experientes profissionais que atuam no país. Optamos por formar um grupo de entrevistados que fosse o mais equilibrado possível em termos de gênero (homens e mulheres) e com reconhecida experiência no exercício do jornalismo, incluindo profissionais da chamada imprensa tradicional e jornalistas de veículos independentes que atuam em diferentes meios de comunicação, utilizam de maneira recorrente as mídias sociais para se comunicar com o público e postam notícias e comentários em suas coberturas jornalísticas. São eles: Bárbara Mengardo, 29 anos, editora do portal jurídico Jota, especializado em questões jurídicas, sediado em Brasília; Daniela Pinheiro, 45 anos, diretora de redação da Revista Época; 3. Daniel Bramatti, 49 anos, editor do Estadão Dados, coordenador do Estadão Verifica e presidente da Associação Brasileira de Jornalismo Investigativo (Abraji); 4. Flávia Oliveira, 48 anos, comentarista dos telejornais Studio I e Edição das 18h, ambos da Globonews; 5. Gabriela Moreira, 37 anos, repórter da ESPN Brasil; 6. João Paulo Charleaux, 39 anos, repórter especial do Nexo Jornal; 7. Marcelo Beraba, 67 anos, diretor da sucursal do jornal Estado de S. Paulo, em Brasília;8. Marcelo Rech, 58 anos, vice-presidente Editorial e Institucional do Grupo RBS; 9. Mariza Tavares, 59 anos, autora de um blog sobre o tema longevidade no 
site de notícias G1, da TV Globo, e de uma coluna sobre gestão de carreiras no portal Letras \& Lucros; e 10. Octavio Guedes, 51 anos, comentarista do Bom Dia Rio, da TV Globo, e do Studio I, da Globonews. Foram realizadas para este estudo quase dez horas de entrevistas gravadas, com ciência dos entrevistados, entre os dias 23 de maio e 20 de junho de 2018. As entrevistas foram realizadas, presencialmente, na cidade do Rio de Janeiro, e também via Skype com jornalistas que atuam em outras cidades. Na pesquisa de Mestrado que deu origem a este trabalho foram aplicadas cinco categorias na análise qualitativa das entrevistas, as quais, como sugere Duarte (2017), auxiliam na organização dos depoimentos ${ }^{4}$. Neste trabalho são apresentados os principais resultados sistematizados referentes à aplicação dacategoria "Definindo as Notícias Falsas", com o intuito de se alcançar o resultado pretendido, uma definição conceitual mais precisa das fakenews.

Para Octávio Guedes, comentarista do Bom dia Rio, da TV Globo, as Fake News se equivalem ao que antes, no jornalismo, era conhecido como boato, uma informação que não tinha "materialidade". "Na época da mídia impressa, o que dava materialidade ao fato era o papel, a impressão; logo, se era boato [esse boato, no bom jornalismo] não era publicado e, portanto, não tinha materialidade", afirma o jornalista. Hoje, segundo ele, o que dá "materialidade" à Fake News é a rede social na internet. Flávia Oliveira, comentarista da Globonews, também destaca que a "notícia falsa com outros nomes sempre existiu". "[eu] Cobria mercado financeiro, quinta-feira era dia de boato. Tinha uma tensão instalada, o ti-ti-ti, as maldades relacionadas à pesquisa eleitoral, a indicadores econômicos e à vida pessoal, eventualmente, de políticos, [de pessoas] da economia". A diferença hoje está, segundo ela, em "uma escala e em uma frequência muito maiores e, portanto, em um poder destrutivo mais forte do que jamais anteriormente, produto da revolução

\footnotetext{
${ }^{4}$ As cinco categorias utilizadas, elaboradas a partir da ampla revisão bibliográfica realizada, são: "Verdadeiro x Falso", "Reconfigurações e Desafios do Jornalismo", "Papel e Função dos Jornalistas" "Impacto das Fake News no Trabalho Jornalístico" e "Definindo as Notícias Falsas".
}

João Pessoa - Brasil | ANO 7 VOL.7 N.1 | JAN./JUN. 2020 | p. 34 a 53 


\section{ANEORA}

Beatriz BECKER - Francisco GOES

tecnológica, da internet e das mídias sociais", associado à perda de relevância da mídia convencional. Mariza Tavares, colunista do G1, ressalta que o fenômeno das fakenews não é mesmo novo: "Nós todos jornalistas mais velhos sempre convivemos com notícias falsas, com notícias plantadas [jargão usado para se definir notícia manipulada, com intenção deliberada no campo político ou econômico]". O problema, para ela, hoje, é a velocidade advinda das tecnologias e da internet, por um lado; e, ao mesmo tempo, o "empoderamento" de todos para produzir conteúdo informativo: "Se todo mundo produz conteúdo, o Jornalismo, tal como é conhecido, não tem capacidade de [gerar] todos esses filtros". Assim, as fakenews ganharam abrangência planetária, diz Mariza.

Marcelo Beraba, chefe da sucursal de O Estado de S. Paulo em Brasília, entende as fakenews como mais um "modismo" do jornalismo, comparável a outros movimentos como o jornalismo literário, o jornalismo investigativo, o jornalismo de precisão e, mais recentemente, o jornalismo de dados. "Esses movimentos, quando surgem, surgem em momentos de crise ou de necessidade de renovação [do jornalismo], e só depois vão ganhando corpo", afirma Beraba. Para o jornalista, embora as plataformas digitais tenham "exponenciado" as notícias falsas, o jornalismo enfrenta essa questão "desde sempre". Daniela Pinheiro, editora da revista Época, reconhece, porém, que existe dificuldade para se definir o que é notícia falsa e muitas vezes se confunde notícia falsa com jornalismo "ruim". "Mas pode ser também o blefe, a notícia plantada com alguma finalidade, algo que a imprensa faz toda hora", destaca Daniela. Segundo Daniel Bramatti, editor do Estadão Dados, as notícias falsas são um fenômeno decorrente da "banalização" da produção de conteúdo informativo, o que resulta, por sua vez, do desenvolvimento da tecnologia. O jornalista argumenta que as fakenews são conteúdos que se valem das divisões ideológicas da sociedade, estimulando e aprofundando essas divisões, e estão imbricadas em interesses econômicos e ganhos financeiros: "O que se busca agora é clique mesmo", diz o jornalista. Ele 
ressalta que as notícias mais acessadas em plataformas sociais na internet decorrentes de operações humanas e/ou de algoritmos definem o que vemos na nossa timeline ou o que é selecionado para nós nos mecanismos de busca na internet e promovem conteúdos que geram mais engajamento. "É algo absolutamente destrutivo e deletério para qualquer conteúdo mais aprofundado e com nuances".

Marcelo Rech, presidente da Associação Nacional de Jornais (ANJ), define, por sua vez, a notícia falsa como "aquela que é produzida deliberadamente com sentido de desinformar". Para ele, notícia falsa se distingue da notícia errada que, por algum problema, imperícia do jornalista ou da fonte, resultou em um erro de informação. A diferença, segundo ele, é que a notícia falsa busca, por desejo ou intenção deliberada, criar uma informação errônea com sentido de atingir algum objetivo. "Pode ser desde a mais ingênua brincadeira ou trote até a intenção de tomada de poder por grupos, ou gerar caos sociais, perseguições étnicas, genocídios, como estamos vendo acontecer". Para João Paulo Charleaux, repórter especial do Nexo Jornal, as fakenews são produzidas e circulam com a intenção de "turvar" o ambiente informativo. Ele reconhece que se trata de um fenômeno de difícil conceituação e sobre o qual se requer uma reflexão aprofundada. Porém, segundo o jornalista, as fakenews podem envolver tanto informações falsas "do começo ao fim", sem conexão com os fatos, com a realidade, mas também podem incluir outras formas de informação, como notícias interpretativas ou o que ele chama de "colunismo de baixa intensidade", em que certa visão analítica de um fato ganha circulação como informação jornalística. Charleaux considera, portanto, que as notícias falsas abarcam a dificuldade que as pessoas têm em "diferenciar gêneros jornalísticos e de tomar artigos de opinião ou análises como valor de notícia". Entretanto, para Gabriela Moreira, repórter da ESPN Brasil, a notícia falsa é aquela na qual há "uma intenção, um objetivo, uma estratégia de enganar o público com uma notícia que não é verdadeira". 


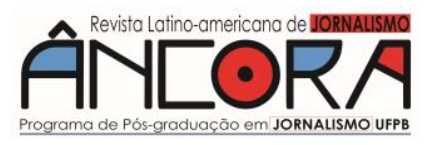

Beatriz BECKER - Francisco GOES

Bárbara Mengardo, editora do portal jurídico Jota, destaca, por sua vez, que notícias falsas são "notícias deturpadas ou exageradas" e que atendem a interesses específicos, que nem sempre são "facilmente" notados.

Identificamos que as fakenews não têm um único significado para os profissionais entrevistados, os quais reconhecem que há dificuldade em definilas. Mas, esses jornalistas não as consideram um fenômeno novo, e podem ser vistas como mais um "modismo" do jornalismo em um momento de crise e comparadas aos boatos de antigamente, embora a tecnologia permita uma difusão e um alcance maiores desses conteúdos informativos na atualidade. Eles ainda ressaltam que as fakenews são orientadas por vieses ideológicos e por interesses econômicos e que representam mudanças pelas quais passa o jornalismo.

\section{Definindo as fakenews}

A partir da reflexão crítica apresentada e das entrevistas realizadas com os jornalistas, foram elaboradas quatro características, abaixo explicitadas, com o intuito de contribuir para uma definição menos difusa das fakenews.

\section{Fakenews afetam a sociedade contemporânea,} especialmente, o jornalismo, refletindo uma desconfiança na credibilidade dos relatos jornalísticos ancorados na objetividade dos fatos e um questionamento sobre a existência de uma verdade. $\mathrm{Na}$ chamada era da pós-verdade, em que as verdades são relativizadas ou parecem se tornar irrelevantes, tendem a prevalecer as opiniões e as crenças pessoais sobre os fatos objetivos. Nesse cenário, a autoridade do jornalismo, concedida, historicamente, por uma outorga do público é questionada, e os jornalistas perdem relevância no papel de mediadores da realidade em decorrência do surgimento de outros atores e plataformas para produção e distribuição de conteúdo nas redes. Hoje, muitas pessoas parecem confiar mais em posts ou em mensagens de amigos, enviadas via plataformas fechadas, como o WhatsApp, do que no jornalismo tradicional, o que tende a 
estimular a formação de "bolhas", comunidades das quais participam pessoas com ideologias e crenças semelhantes, limitando, como consequência, um debate de ideias mais plural.

\section{Fakenews não é algo novo e pode ser comparada, em outra} escala, ao boato de antigamente. Embora jornalistas e pesquisadores identifiquem a proximidade da fakenews com o boato, eles entendem que a singularidade deste fenômeno na atualidade decorre de sua rápida velocidade de disseminação nas redes, com efeitos muito mais expressivos do que o boato para o jornalismo e campos diversos do conhecimento. Os motores para a difusão em larga escala e em tempo real das fakenews na atualidade são tanto as tecnologias de inteligência artificial, como os algoritmos, o big data e os bots, quanto as crenças e as emoções dos indivíduos manifestadas nas redes. Dessa forma, as fakenews minam e tendem a desacreditar o trabalho jornalístico profissional, imbricadas na exploração de crenças e vínculos emocionais e afetivos de grupos de interesse.

\section{Fakenews como um oxímoro, termo que expressa uma} contradição em si mesmo. A principal característica deste aspecto está no paradoxo que a expressão "notícia falsa" encerra. A definição de notícia pressupõe que o relato jornalístico tem como princípio a enunciação da verdade do fato. Logo, não seria possível existir uma notícia falsa, mas sim algo que se assemelha apenas ao formato de uma notícia. Portanto, se as notícias em si não são tidas como falsas, as fakenews poderiam ser então compreendidas como um hibridismo do gênero jornalístico, no qual a estrutura e o formato do texto são mantidos, buscando garantir a credibilidade de uma determinada postagem para atrair o interesse do público, porém sem seguir os princípios de apuração do fato e de construção do acontecimento jornalístico. Esse hibridismo é decorrente não apenas do desenvolvimento e do uso de tecnologias digitais, mas da vontade do público de expressar opinião, desfazendo, consequentemente, a autoridade do jornalismo como enunciador 


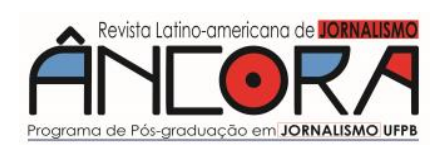

Beatriz BECKER - Francisco GOES

exclusivo do presente em um contexto de engajamentos mais emocionais do que racionais com a informação noticiosa no ambiente convergente.

\section{Fakenews como instância do caos informacional da} sociedade contemporânea, um mecanismo criado por determinados grupos para, deliberadamente, enganar a audiência com o objetivo de obter benefícios políticos e/ou econômicos ou para aprofundar divisões ideológicas na sociedade por meio da disseminação de desinformação (informação fora de contexto ou deturpada). É preciso considerar que a convergência entre as mídias e a maior participação do público na produção e na distribuição de informação nas redes sociais na internet gerou uma miríade de conteúdos e uma hiperabundância de fluxos informacionais. Nesse ambiente de desordem informativa se verifica o espraiamento de informações não credíveis e que contribuem para o ambiente de desinformação contemporâneo. O compartilhamento de fakenews em larga escala provoca prejuízos políticos, econômicos e/ou morais a pessoas, grupos e/ou instituições. A disseminação de fakenews também aprofunda as polarizações existentes entre diferentes grupos da sociedade marcadas, na atualidade, por divisões ideológicas que tendem mais ao sectarismo do que ao diálogo. Outro aspecto relevante das fakenews é a sua apresentação em formato de notícia real, vinculada, em grande medida, ao uso de mecanismos de inteligência artificial (algoritmos, bots, tecnologias de big data). Tanto na visão de jornalistas quanto na de pesquisadores, as fakenews podem ser combatidas via checagem de fatos, uma atividade que, historicamente, é intrínseca ao jornalismo, mas que ganhou novo ímpeto a partir do surgimento de agências independentes de fact-cheking no Brasil e no exterior. Como reação a esse movimento, foram criados departamentos de checagem vinculados às estruturas de organizações jornalísticas tradicionais. 


\section{Considerações finais}

A partir da reflexão teórica sistematizada e das vozes dos jornalistas entrevistados, que colaboraram com esta pesquisa, procuramos apresentar uma definição conceitual mais precisa sobre as fakenews. Em síntese, este trabalho aponta que, no século XXI, as fakenews se constituem como um fenômeno de comunicação decorrente da velocidade com que conteúdos informativos se espalham no ambiente convergente em rede, ainda que sejam semelhantes ao boato, prática social que, historicamente, sempre esteve imbricada nas conversações humanas. Entretanto, a expressão "notícia falsa" é um oxímoro, ou seja, termo que expressa uma contradição em si mesmo, uma vez que a atividade jornalística é baseada em discursos verdadeiros, e não falsos. Contudo, as reflexões sobre as fakenews implicam questionamentos sobre a objetividade e a credibilidade do discurso jornalístico, princípios que ancoram esta prática profissional, quando os recursos editoriais empregados não são transparentes para os leitores.

A participação do público como agente produtor e distribuidor de conteúdo e as tecnologias de inteligência artificial desempenham um papel relevante nos processos comunicacionais no ambiente convergente. Em um contexto de hiperabundância de informação ou de desordem informacional as pessoas tendem a estabelecer vínculos emocionais com as notícias e privilegiam crenças e opiniões pessoais em detrimento de fatos. Esse empoderamento das audiências se inscreve no que se convencionou chamar mais recentemente de era da pós-verdade, quando há uma tendência à indiferença em relação à verdade ou de se considerar as verdades como sendo irrelevantes. Porém, as fakenews são disseminadas nas redes não somente pela cultura participativa ou via mediação jornalística. Atores não humanos, ou seja, mecanismos de inteligência artificial, incluindo robôs, algoritmos e tecnologias de big data pulverizam este fenômeno nas redes sociais.A utilização dessas tecnologias faz emergir "bolhas", nas quais os diferentes 


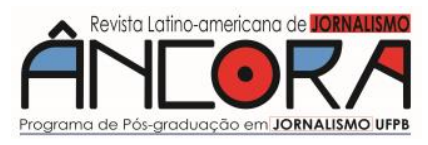

Beatriz BECKER - Francisco GOES

grupos ou comunidades tendem a se fechar em torno de pensamentos únicos, o que não colabora para a pluralidade de percepções da realidade social e para a democracia. Nesse sentido, as pessoas estariam inseridas em um "caos" cultural e informacional no qual estabelecem vínculos emocionais com as notícias e privilegiam crenças e opiniões em detrimento de fatos. As fakenews apontam ainda um hibridismo dos gêneros jornalísticos opinativo e informativo, no qual a estrutura e o formato do texto são mantidos para garantir a credibilidade de uma determinada postagem e atrair o interesse do público, mas sem seguir os princípios de apuração do fato e de construção do acontecimento jornalístico. De tal modo, as fakenews são constituídas com a forma verossímil de uma notícia real, mas que mistura veracidade e falsidade, sem que esse jogo discursivo seja percebido pela audiência ou desperte o interesse do público em checar se, de fato, a informação é confiável, uma vez que esse conteúdo informativo atende às suas crenças e emoções. Assim, as fakenews também podem ser entendidas como estratégia de determinados grupos de interesse para enganar o público, fortalecer relações de poder, acentuar divisões ideológicas na sociedade ou obter vantagens financeiras.

Nesse complexo cenário, entretanto, a reflexão aqui proposta alinha-se ao entendimento de pesquisadores que compreendem as fakenews como parte da desordem informacional existente no mundo contemporâneo. Tal desordem pode operar como um instrumento de fortalecimento de relações de poder, negando fatos e evidências científicas ou historicamente comprovadas. Assim, as fakenews tanto enfraquecem como fortalecem o jornalismo. Inseridas no atual processo de descentralização da produção noticiosa na internet, as fakenews contribuem para a perda do "monopólio" dos jornalistas como contadores de histórias do presente e da autoridade institucional do jornalismo. A falta de qualidade de apuração e o excesso de informações tendem a consolidar o ambiente de boato em rede. Entretanto, num cenário em que as fakenews operam turvando o ambiente informativo, o jornalismo tem o potencial de elucidar assuntos relevantes, amparado na curadoria 
humana das informações, na checagem da veracidade das notícias, na contextualização dos fatos, no pluralismo de pontos de vista sobre acontecimentos relevantes para a sociedade e na diversidade de pautas e fontes, capazes de contribuir para as sociedades democráticas. Contudo, a independência editorial do jornalismo é fundamental para que se constitua como prática social relevante na atualidade e contribua para a democracia.

\section{Referências}

ALLCOT, Hunt; GENTZKOW, Matthew. Social Media and Fake News in the 2016 Election. [Working Paper 23089]. National Bureau of Economic Research, Cambridge, MA.Abr. 2017. Disponível em:

http://www.nber.org/papers/w23089.pdf. Acesso em: 20 maio 2019. CASTRO, Julio Cesar Lemes de. Pós-verdade e o papel do jornalismo: neoliberalismo, Brexit/Trump e redes sociais.Anais [...]Encontro Nacional de Pesquisadores em Jornalismo. Associação Brasileira de Pesquisadores em Jornalismo (SBPJor). ECA/USP - São Paulo, 15 nov. 2017. Disponível em: http://sbpjor.org.br/congresso/index.php/sbpjor/sbpjor2017/paper/viewFile/6 87/508. Acesso em: 15 jul. 2019.

COROMINA, Óscar;PADILLA, Adrián. Analysis of desinformation regarding the referendum on 1 October detected by 'MalditoBulo'. Quadernsdel CAC, Barcelona: Conselho do Audiovisual da Catalunha, v. XXI, n. 44, jul. 2018. DUARTE, Jorge. Entrevista em Profundidade. In: DUARTE, Jorge; BARROS, Antonio. (orgs). Métodos e Técnicas de Pesquisa em Comunicação. São Paulo: Atlas, 2017, p.62-83.

FRANCISCATO, Carlos Eduardo. Um Agudo Diagnóstico do Jornalismo: entre o desenvolvimento e a inovação. In: SILVA, Fernando F.;SOUSA, Joana B.;NUNES, Pedro. Escutas sobre o Jornalismo.2017, p. 85-87. E-book. Postado em Ancora - Revista Latino-Americana de Jornalismo, João Pessoa: Universidade Federal da Paraíba, v. 4, n. 2, 2017. Disponível em: http://www.periodicos.ufpb.br/ojs/index.php/ancora/article/view/40091/2012 7. Acesso em: 26 jul. 2019.

GUESS, Andrew;NYHAN, Brendan;REIFLER, Jason. Selective Exposure to Misinformation:Evidence from the consumption of fake news during the 2016 US presidential campaign. Conselho de Pesquisa Europeia. 2018. Disponível em: https://www.dartmouth.edu/ nyhan/fake-news-2016.pdf. Acesso em: 10 jul. 2019.

GONZALO, Sara Suárez. Your likes, your vote? Big personal data exploitation and media manipulation in the US presidential election campaign of Donald Trump in 2016.Quadernsdel CAC,Barcelona: Conselho do Audiovisual da Catalunha, v. XXI, n. 44, 2018. 


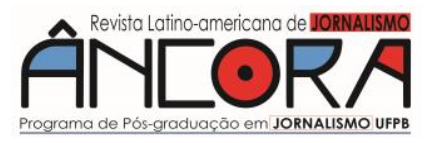

Beatriz BECKER - Francisco GOES

KAKUTANI, Michiko. A morte da verdade.Notas sobre a mentira na era Trump.Rio de Janeiro: Intrínseca, 2018. KISCHINHEVSKY, Marcelo. Cinco Lições de 2018 para os jornalistas. 0 mundo mudou, e muito. Não se fazem mais futuros como antigamente. 2018.Disponível em:https://projetocolabora.com.br/cidadania/cinco-licoesde-2018-para-os-jornalistas/. Acesso em: 13 ago. 2019. LISBOA, S.; BENETTI, M. O Jornalismo como Crença Verdadeira Justificada. BrazilianJournalismResearch, v.11, n.2, 2015. Disponível em: https://bjr.sbpjor.org.br/bjr/article/view/664/666.Acesso em: 17 ago.2019. Martin, Nora. Journalism, the Pressures of Verification and Notions of PostTruth in Civil Society. Cosmopolitan Civil Societies: An

Interdisciplinary Journal, Austrália, v. 9, n. 2, p. 41-55, 2017. Disponível em: http://epress.lib.uts.edu.au/journals/index.php/mcs/article/view/5476.

Acesso em: 21 jul. 2019.

MEDITSCH, Eduardo. O Jornalismo como prática cultural de produção do conhecimento. In: SILVA, Fernando F.;SOUSA, Joana B.; NUNES, Pedro (2017). Escutas sobre o Jornalismo, 2017, p.43-56. E-book. Postado em Ancora - Revista Latino-Americana de Jornalismo, João Pessoa: Universidade Federal da Paraíba, v. 4, n. 2, 2017. Disponível em: http://www.periodicos.ufpb.br/ojs/index.php/ancora/article/view/40091/2012 7. Acesso em: 16 jul. 2019.

McNAIR, Brian. Fake News- Falsehood, fabrication and fantasy in Journalism. New York: Routledge, 2017. MIRANDA, Amanda; VIEIRA, Lívia de Souza. Intercept Lança Falhas na Lava Jato e Lança Discussões sobre Ética e Interesse Público. Objethos, Observatório de Ética Jornalística. Disponível em: https://objethos.wordpress.com/2019/06/10/the-intercept-falhas-da-lavajato-etica-e-interesse-publico/. Acesso em: 15 ago. 2019.

NYHAN, Brendan; REIFLER, Jason. The effects of fact-checking threat Results from a field experiment in the states. New American Foundation, out. 2013. Disponível em:https://www.dartmouth.edu/ nyhan/nyhan-reiflerreport-naf.pdf. Acesso em: 08 ago. 2019.

PARISIER, Eli. 0 filtro invisível. O que a internet está escondendo de você. Rio de Janeiro: Jorge Zahar Editor, 2011.

PRADO, Emili. Fakenews, algorythmsandfilterbubbles.Quadernsdel CAC,Barcelona: Conselho do Audiovisual da Catalunha,v. XXI, n. 44, jul. 2018.

PRADO, José Luiz Aidar; PRATES, Vinicius. Sintoma e fantasia no capitalismo comunicacional. São Paulo: Estação das Letras e Cores, 2017.

RESENDE, Fernando. O jornalismo e a enunciação: perspectivas para um narrador jornalista. Contracampo, Rio de Janeiro: UFF, 12,p. 85-101, 2005. Disponível em: 
http://www.contracampo.uff.br/index.php/revista/article/view/560. Acesso em: 31 jun. 2019.

REUTERS INSTITUTE FOR THE STUDY OF JOURNALISM. How can we combat fake wews? - The role of plataforms, media literacy and journalism.Mar. 2017. Disponível em:

https://reutersinstitute.politics.ox.ac.uk/risj-review/how-can-we-combat-fakenews-role-platforms-media-literacy-and-journalism. Acesso em: 09 jun. 2019. TANDOCJR., Edson C.;WEILIM, Zheng; LING, Richard. Defining "fake news" A typology of scholarly definitions. Digital Journalism,v.6, n. 2, p. 137-153, 2018. Disponível em:

https://www.tandfonline.com/doi/abs/10.1080/21670811.2017.1360143. Acesso em: 16 jun. 2019.

WARDLE, Claire, DERAKHSHAN, Hossein. Report: Information Disorder: Toward an interdisciplinary framework for research and policy making.Conselho Europeu, Estrasburgo, out. 2017. Disponível em: https://rm.coe.int/information-disorder-toward-an-interdisciplinaryframework-for-researc/168076277c. Acesso em: 04 jul. 2019. 